\section{Most studied single cell}

Biochemistry and Pharmacology of Platelets. (Ciba Foundation Symposium 35, New Series.) Pp. viii 352. (Elsevier/Exerpta Medica/North-Holland: Amsterdam, Oxford and New York, 1975.) \$23.95; Dfl. 59.50.

YET one more book on platelets! So prestigious a gathering as a Ciba Symposium, however, can be relied on to produce an authoritative book. What is the fascination that is fast making the platelet the most studied single cell? Partly, it is easily isolated yet more complex and interesting than the red cell: an understanding of it may contribute incalculably to the prevention of thrombosis. In addition, it is studied almost as a type cell. The actin and mysin are similar to that found in muscle.. Dr Cohen exclaims "the amazing thing is that fibroblasts respond to exactly the same stimuli as platelets do". Biological amines and monoamine oxidase drugs often have analogous effects on platelets and on the central nervous system. Another reason for the fascination is the close link of platelet biochemistry and pharmacology to platelet physiology. Indeed the contributors are as interested in pseudopod formation and sticky membranes as in the metabolic pathways involved: in fact large areas of platelet physiology are covered.

The basic membrane change involved in platelet 'stickiness' remains elusive but the membrane response to stimuli and the part played by the adenine nucleotides among many others, are presented in detail. The interrelationships between actin and myosin and the kinase of platelets and other cells are discussed. The pharmacology of platelet aggregation induction, its many inhibitors and the prostaglandins and aspirin effects are all well covered. The 'Platelet Release Reaction' has now become two: I from dense granules: II from $\alpha$ granules. Glycolysis, mineral elements, the part played by calcium and the gangliosides-it is all here including receptor action and bioamine storage.

Although not wishing to detract from the interest of the many detailed studies presented, one questions the relevance of some to intact platelets in vivo. They are so sensitive that demonstrable alterations occur, for example, with a poor venepuncture or after a fatty meal. Although the effect of prostaglandins on the biochemistry is extensively considered, I would have liked more space devoted to the prostaglandin $E_{1}$ precursors and platelet inhibition-that elusive therapeutic goal.

As usual the standard of production is excellent. Professor Born and Ciba are to be congratulated, particularly on the editing of the discussion. But even so I don't find this nearly so rewarding as the papers themselves. This book is not easy going but is a recommended and masterly survey up to mid-1975 for physiologists and haematologists as well as biochemists and pharmacologists.

\section{Learning theory}

Elements of a Two-Process Theory of account of a wide range of animal beLearning. By J. A. Gray. Pp. $\mathrm{x}+423$. haviour, however, there is a strong (Academic: London, New York and tendency to rely on a small number San Francisco, 1975.) $£ 6.60 ; \$ 16.50$.

IN the past twenty years the study of animal learning has suffered a sharp loss in prestige; in the $1950 \mathrm{~s}$ it was seen as the most developed and 'scientific' topic within experimental psychology; and great, although perhaps unrealistic, hopes were held out that it would illuminate our understanding of human behaviour and personality. These hopes have not been realised and, with the development of the cognitive and information-processing approaches to human behaviour, animal psychology is often seen as an unattractive and somewhat stagnant backwater with few connections with the wider currents of psychological thought. Dr Gray has argued that the study of animal learning cannot be divorced from human psychology, and isolated examples, but rather illustrate that it has much to tell us about a weakness present throughout the human personality. In this book he still book; the unwary reader may easily sees learning theory as providing a be misled in such cases. The author "scaffolding for a theory of the physiological basis of personality".

It is a pleasure to read a book which conveys such enthusiasm for the subject particularly when it is written with style and clarity; it is by no means an elementary book and makes considerable demands on the reader, but no- dist learning theory remains an interesting reinforcement largely disappear. This and challenging study, or that recent logical coup, however, is achieved by work on animal learning is providing making use of the concept of 'goal- directed drive', which is foreign to most forms of learning theory, and which, although undefined, seems to subsume all the goal-directed aspects of motivation. The subsequent logical argument merely spells out the consequences of the author's definitional decisions and takes our understanding of motivation little further.

The whole book is an attempt to provide a unified account of learning which the author describes as a twothe effects of superimposing an process theory. It is curious therefore
appetitive conditioned stimulus on that the theory proposed relies very instrumental behaviour maintained by heavily on the classical conditioning an appetitive reinforcer is confused component and, as the author admits, and conflicting; there is at least as is very similar to Mowrer's 1960 much reason to suppose that it theory, which Mowrer himself desuppresses instrumental responding as cribed as a one-factor theory. In hat it increases it as Dr Gray main- Gray's, as in Mowrer's, model the tains. Rescorla is cited as supporting instrumental component serves only to the idea of backward conditioning, direct the animal towards or away where the experiments in question from stimuli which possess positive reinforcing properties; and in spite of the earlier discussion of 'goal-directed drive', the way in which goal directedness enters into these relationships is not discussed. What we seem to have is also has a tendency to attempt to resolve issues by definition or logic. short, the author provides a plausible Thus it is argued that the word drive account of how stimuli becomes is used to describe three rather differ- attractive or aversive, but very little ent concepts which are logically and insight about instrumental behaviour. operationally distinct; it is then

I feel that these shortcomings make the book unsuitable for undergraduate reading; but this is a book which research workers in the field will find sometimes illuminating, sometimes irritating but always interesting.

M. S. Halliday 